\title{
Penilaian Implementasi e-Government di PUSTEKOM Kemendikbud berbasis metode PEGI
}

\author{
Puji Rahayu ${ }^{\mathrm{a}, *}$, Dana Indra Sensuse ${ }^{\mathrm{b}}$ \\ ${ }^{a}$ Fakultas Teknologi Informasi, Perbanas Institute \\ ${ }^{a, b}$ Lab e-Gov, Fakultas Ilmu Komputer, Universitas Indonesia
}

Naskah Diterima : 26 Juli 2017; Diterima Publikasi : 30 Oktober 2017

DOI : 10.21456/vol7iss2pp139-145

\begin{abstract}
According to the Survey UN (United Nations) in 2014, e-government and innovation can provide major opportunities to transform the public administration becomes a tool of sustainable development, provide services more transparent and more accountable. Formerly, the development of government services can be done with a variety of channels, either through online services, big data, social media, mobile applications, or cloud computing, have expanded our perception of e-government services. The research aims to assess the level of achievement of e-Government implementation in the Ministry of Education and Culture of the Republic of Indonesia. Assessment is measured by the Indonesian e-Government Rating framework. The data in this research are obtained by qualitative approach and descriptive data analysis. The finding of this research that the implementation of e-Government in Ministry of Education and Culture in the category of "Very Good". Based on such an assessment, given the recommendation: assemblying policies Governance of ICT, aligning the ICT Master Plan by principle of ICT Governance, fulfilling documents related to human Resources of ICT and the application documents, the standardization of domain labeling and e-education, completing information systems/ technogy of management and organizational design, assemblying the development plan of e-education content, and development plans of information system and information technology.
\end{abstract}

Keywords: Indonesian Ministry of Education and Culture; Indonesian e-Government Ranking (PEGI); E-Government.

\begin{abstract}
Abstrak
Menurut Survey United Nations tahun 2014, e-government dan inovasinya dapat memberikan peluang yang signifikan untuk mengubah administrasi publik menjadi alat pembangunan berkelanjutan, memberikan layanan yang lebih transparan dan lebih akuntabel. Perkembangan layanan pemerintah dapat dilakukan dengan berbagai saluran, baik melalui layanan online, big data, social media, aplikasi mobile, atau cloud computing, telah memperluas persepsi umum terhadap layanan egovernment. Penelitian ini bertujuan melakukan penilaian tingkat capaian implementasi e-Government pada Kementerian Pendidikan dan Kebudayaan. Penilaian diukur dengan kerangka kerja Pemeringkatan e-Government Indonesia. Data dalam penelitian ini diperoleh dengan pendekatan kualitatif dan analisis data deskriptif. Dari hasil penelitian didapatkan bahwa implementasi $e$-Gov di Kementerian Pendidikan dan Kebudayaan dalam kategori "Sangat Baik". Berdasarkan asesmen tersebut, diberikan rekomendasi: hendaknya disusun kebijakan terkait Tata Kelola TIK, menyelaraskan Rencana Induk TIK dengan rumusan Tata Kelola TIK, melengkapi dokumen yang terkait dengan sumberdaya manusia TIK, melengkapi dokumen aplikasi, standarisasi penamaan domain, standarisasi layanan e-pendidikan, melengkapi desain manajemen dan organisasi system informasi/ teknologi informasi, melengkapi rencana pengembangan konten e-pendidikan, dan rencana pengembangan sistem dan teknologi informasi.
\end{abstract}

Kata kunci: Kemendikbud; Pemeringkatan e-Government Indonesia (PeGI); E-Government

\section{Pendahuluan}

Dalam Pembukaan Undang-Undang Dasar (UUD) Negara Republik Indonesia tahun 1945 dinyatakan bahwa salah satu tujuan Negara Kesatuan Republik Indonesia (NKRI) adalah mencerdaskan kehidupan bangsa, sejalan dengan Pembukaan UUD 1945, batang tubuh konstitusi tersebut pada pasal 20, pasal 21, pasal 28 c ayat (1), pasal 31 dan pasal 32 mengamanatkan bahwa pemerintah mengusahakan dan menyelenggarakan satu sistim pendidikan nasional dan memajukan kebudayaan nasional untuk meningkatkan keimanan dan ketakwaan kepada Tuhan Yang Maha Esa, serta akhlak mulia dalam rangka mencerdaskan kehidupan bangsa yang diatur dalam undang-undang.

\footnotetext{
*) Penulis korespondensi: puji.rahayu@ @erbanas.id puji.rahayu41@ui.ac.id
} 
Dengan amanat UUD 1945, Kementerian Pendidikan dan Kebudayaan (Kemendikbud) menyelenggarakan pendidikan, meliputi ketersediaan, memberikan layanan pendidikan yang merata di seluruh wilayah, karena pendidikan merupakan hak asasi manusia dimana setiap warga negara berhak memperoleh pendidikan yang bermutu dan berhak memperoleh layanan pendidikan yang terjangkau dan dapat dinikmati oleh seluruh lapisan masyarakat tanpa adanya diskriminasi.

Pembangunan kebudayaan diselenggarakan dalam rangka peningkatan sosial budaya dan kehidupan beragama yang terkait erat dengan pengembangan kualitas hidup tercapainya suasana kehidupan masyarakat Indonesia yang berakhlak mulia, bermoral, beretika, berbudaya dan beradab secara harmonis dalam berkehidupan yang sejalan dengan nilai-nilai kebangsaan. Berdasarkan Peraturan Presiden RI Nomor 92 Tahun 2011 tentang Perubahan Kedua Atas Peraturan Presiden Nomor 24 Tahun 2010 Tentang Kedudukan, Tugas, dan Fungsi Kementerian Negara Serta Susunan Organisasi (LAKIP-Kemendikbud, 2013; Kementerian Pendidikan dan Kebudayaan, 2010).

Pada tahun 1976, Menteri Pendidikan dan Kebudayaan membentuk Tim TKPK (Teknologi Komunikasi untuk Pendidikan dan Kebudayaan) berkedudukan di Jakarta, Semarang, Yogyakarta, dan Surabaya. Kemudian pada 1978, Tim TKPK ditingkatkan menjadi Pusat Teknologi Komunikasi Pendidikan dan Kebudayaan, disingkat Pusat TKPK, yang sekarang ini dikenal dengan sebutan PUSTEKKOM berdasarkan Keputusan Presiden Republik Indonesia Nomor 27 Tahun 1978 tertanggal 31 Agustus 1978 dan Surat Keputusan Menteri Pendidikan dan Kebudayaan Nomor: 0145/O/1979 tertanggal 30 Juni 1979 yang diperbaharui dengan Surat Keputusan Menteri Pendidikan dan Kebudayaan Nomor: 0222g/O/1980.

Sejak tahun 2000, Pustekkom memperluas lingkup kerjanya dengan menambahkan unsur teknologi informasi ke dalam bidang tugasnya, sehingga nama lembaga ini menjadi Pusat Teknologi Informasi dan Komunikasi Pendidikan, dengan akronim tetap PUSTEKKOM (ICT Center for Education).

Sampai saat ini Pustekkom mempunyai 3 Balai Pengembang Media dan sejumlah unit pelaksana teknis (UPT) di daerah berupa 29 UPTD/Balai Tekkom. Tahun 2005, Pustekkom berada langsung di bawah Sekretariat Jenderal Departemen Pendidikan Nasional sesuai dengan Permendiknas No. 23 Tahun 2005 tentang Organisasi dan Tata Kerja Pusat di lingkungan Departemen Pendidikan Nasional. Pustekkom sebagai unit kerja yang mendukung unit kerja lain dalam bidang Informasi Teknologi dan Komunikasi di Kemetrian Pendidikan dan Kebudayaan memberikan layanan kepada masyarakat umum, kepada dunia kerja dan pendidikan untuk melihat bagaimana proses pembuatan media pembelajaran yang berbasis Audio, Televisi, Multimedia serta bagaimana pengelolaan jaringan pendidikan nasional (Kementerian Pendidikan dan Kebudayaan, 2010; Kementerian Pendidikan dan Kebudayaan, 2012; Kementerian Pendidikan dan Kebudayaan, 2014).

Untuk mengukur sejauh mana tingkat keberhasilan tata kelola teknologi informasi di Kemendikbud, digunakanlah suatu kerangka yang dapat digunakan untuk menganalisa dan menghasilkan output berupa informasi yang akan merepresentasikan tingkat keberhasilan tata kelola TI di Kemendikbud. Berkenaan dengan hal tersebut perlu dianalisis sejauh mana tingkat pemanfaatan Teknologi Informasi dan Komunikasi di kemendikbud dengan menggunakan Pemeringkatan e-Government Indonesia (PeGI) berdasarkan Surat edaran Menteri Komunikasi dan Informatika Nomor 07/SE/M.KOMINFO/10/2011 tentang Pemeringkatan e-Government Indonesia (PeGI).

PeGI adalah suatu model yang dibuat oleh Direktorat e-Government, Direktorat Jenderal Aplikasi dan Telematika, Kementerian Komunikasi dan Informatika (Kementerian KOMINFO) yang dapat digunakan sebagai solusi untuk menganalisis e-Government. PeGI memiliki 5 dimensi assessment yang dikaji. Kelima dimensi tersebut adalah kebijakan, kelembagaan, infrastruktur, aplikasi dan perencanaan. Masing-masing dimensi tersebut memiliki bobot yang sama dalam penilaian karena semuanya penting, saling terkait dan saling menunjang antara satu dengan yang lainnya Kemkominfo (2011); Kemkominfo (2012).

Penelitian ini bertujuan melakukan penilaian implementasi $e$-Gov di Kemendikbud di tahun 2014, diukur dengan menggunakan kerangka kerja PeGI. Diharapkan hasil penilaian ini dapat dijadikan acuan bagi pengembangan dan pemanfaatan teknologi informasi dan komunikasi serta meningkatkan profesionalisme kinerja Kemendikbud dalam rangka memperlancar arus informasi dan meningkatkan kualitas pelayanan kepada masyarakat.

\section{Kerangka Teori}

\subsection{Pengembangan E-government}

Implementasi e-gov sudah diinisiasi oleh organisasi dunia PBB, pengertian $e$-Gov berdasarkan definisi United Nations Survey (United Nations, 2014), adalah penggunaan ICT dan aplikasinya oleh pemerintah untuk penyediaan informasi dan pelayanan publik kepada masyarakat. Di tahun 2014 ranking Indonesia dalam E-Gov Development Index mengalami peningkatan, itu artinya implementasi egov di Indonesia juga mengalami peningkatan. Implementasi e-gov oleh pemerintah diatur dalam Instruksi Presiden, tentang Kebijakan dan Strategi Nasional Pengembangan e-Gov dimana kebijakan 
tersebut merupakan payung hukum dari seluruh kebijakan detail teknis di bidang e-Gov (Republik Indonesia, 2003a; Republik Indonesia, 2003b). Pengembangan e-government merupakan upaya untuk mengembangkan penyelenggaraan kepemerintahan yang berbasis elektronik, dalam rangka meningkatkan kualitas layanan publik secara efektif dan efisien.

Melalui pengembangan e-government dilakukan penataan sistem manajemen dan proses kerja di lingkungan pemerintah dengan mengoptimasikan pemanfaatan teknologi informasi. Inpres ini menginstruksikan agar tiap instansi pemerintah melakukan perumusan strategi/action plan untuk lingkungan instansinya masing-masing. Implementasi $e$-Gov di Indonesia dilandasi adanya keinginan untuk memberikan kemudahan kepada masyarakat dalam memperoleh informasi sebagai wujud pelayanan terbaik kepada masyarakat. Untuk mengukur keberhasilan reformasi birokrasi, untuk tiap lembaga Kementerian dan pemerintah daerah maka diterbitkanlah Kepmen PAN \& RB No. 11 Tahun 2011, tentang Kriteria dan Ukuran Keberhasilan Reformasi Birokrasi, salah satu kriteria keberhasilan reformasi birokrasi adalah adanya pengembangan $e$ government pada masing - masing Kementerian/ Lembaga dan Pemerintah Daerah, dikutip dari (Kemenpan, 2011; Kementerian Pendidikan dan Kebudayaan, 2014).

Pada lingkup Kemendikbud, Menteri pendidikan mengeluarkan peraturan Menteri tentang Tata Kelola TIK di lingkungan Kementerian Pendidikan dan Kebudayaan Republik Indonesia, Menteri Pendidikan dan Kebudayaan, 2013; Pustekkom, 2013), yang mengatur keselarasan perencanaan, pengembangan, dan implementasi teknologi informasi dan komunikasi perlu adanya pengelolaan teknologi informasi dan komunikasi secara terpadu di lingkungan Kementerian Pendidikan dan Kebudayaan. Untuk itu disusunlah Renstra ependidikan yang dilaksanakan oleh Pustekkom unit pendukung TIK dibawah setjen Kemdikbud (Kementerian Pendidikan dan Kebudayaan, 2010; Pustekkom, 2013).

\subsection{Dimensi Pemeringkatan e-Goverenment Indonesia $(P e G I)$}

PPeGI memiliki 5 dimensi penilaian sebagaimana terlihat pada Gambar 1. Dalam pelaksanaan pemeringkatan, telah ditentukan 5 dimensi yang dikaji yaitu: Kebijakan, Kelembagaan, Infrastruktur, Aplikasi, dan Perencanaan.

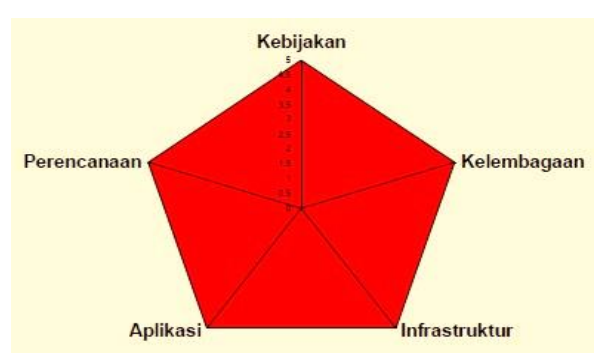

Gambar 1. Lima dimensi asesmen pemeringkatan e-Government Indonesia

Masing-masing dimensi itu memiliki bobot yang sama dalam penilaian karena semuanya penting, saling terkait dan saling menunjang antara satu dengan yang lainnya, Kemkominfo (2013).

\subsection{Proses Assessment}

Proses assessment lapangan dalam rangka penilaian e-Government Indonesia, dilakukan dengan:

a. Mengumpulkan indikator dari 5 dimensi dari dalam materi presentasi atau materi pendukung, yang berbentuk antara lain:

1) Dokumen (naskah, foto, grafik, bagan dan lain-lain)

2) Halaman web

3) Laporan

4) Buku-buku panduan, pedoman, peraturan, keputusan internal, hasil audit

b. Indikator diharapkan menggambarkan

1) Sumber daya

2) Fasilitas

c. Assessor melakukan inventarisasi, pemeriksaan dan penilaian terhadap indikator di atas dan relevansinya terhadap pengembangan dan implementasi e-government di lingkungan Kemendikbud.

\subsection{Panduan Penilaian}

Secara umum penilaian terhadap tata kelola eGoverment Indonesia [7] adalah sebagai berikut:

a) Nilai 1,0 - 1,49 (sangat kurang)

Indikator tidak ada atau sangat kurang dari segi jumlah dan kualitas

b) Nilai 1,5 - 2,49 (kurang)

Indikator sudah ada namun masih perlu ditambah dari segi jumlah dan ditingkatkan secara kualitas

c) Nilai 2,5 - 3,49 (baik)

Indikator berjumlah dan berkualitas cukup baik dan dapat dilihat membawa dampak positif pada pemanfaatan e-government masih namun diperlukan perbaikan perbaikan untuk menjaga kelangsungan implementasi e-government pada masa yang akan datang. 
d) Nilai 3,5 - 4,0 (sangat baik)

Indikator baik dari segi jumlah maupun kualitas sangat baik. Dampak pada implementasi e-government terlihat sangat nyata. Kesiapan untuk terus dikembangkan pada masa datang sudah terlihat jelas.

Sedangkan untuk penilaian indikator dari tiap sub dimensi dalam kuesioner menggunakan skala dengan rentang nilai $1-4$

a) Nilai 1 , Indikator tidak ada sama sekali segi jumlah dan kualitas

b) Nilai 2, Indikator dalam rencana (ada dokumen pendukung adanya rencana)

c) Nilai 3, Indikator untuk dokumen ada namun sebagian (belum lengkap)

d) Nilai 4, Indikator lengkap dari segi jumlah maupun kualitas dokumen.

\section{Metode}

\subsection{Analisis Kebutuhan Data}

Data dimensi dan penilaian indikator yang diperlukan guna mendukung penelitian ini dengan metoda Pemeringkatan $e$-Government Indonesia.

\subsection{Metode}

Metode yang digunakan bersifat kualitatif deskriptif dengan teknik pengambilan data melalui studi dokumen, observasi, penyebaran kuesioner dan depth interview. Penggunaan metode ini dimaksudkan sebagai prosedur pemecahan masalah yang diselidiki dengan menggambarkan atau melukiskan keadaan Kemendikbud pada saat sekarang berdasarkan fakta- fakta yang tampak atau sebagaimana adanya. Penelitian ini mendeskripsikan fenomena/ peristiwa yang ada di dalam implementasi $e$ - Gov di Kemendikbud sebagai bentuk pelayanan kepada masyarakat yang menggunakan teknologi informasi di dalam pelaksanaannya.

Penelitian dilakukan dengan menyebarkan angket atau kuesioner kepada para responden yang terkait dengan tata kelola TI di Kemendikbud.

Tabel 1. Tahapan penelitian

\begin{tabular}{lll}
\hline Tahapan & Periode & Deskripsi \\
\cline { 1 - 2 } $\begin{array}{l}\text { Pengambilan } \\
\text { data awal }\end{array}$ & $\begin{array}{l}\text { 15 Sept }- \\
6 \text { Okt } 2014\end{array}$ & Melakukan observasi \\
$\begin{array}{l}\text { Pengambilan data } \\
\text { lanjutan }\end{array}$ & $\begin{array}{l}7 \text { Okt }- \\
9 \text { Nov 2014 }\end{array}$ & $\begin{array}{l}\text { Menyebarkan survei } \\
\text { dan wawancara }\end{array}$ \\
Analisis Hasil & $\begin{array}{l}10-28 \text { Nov } \\
2014\end{array}$ & Melakukan pengukuran \\
$\begin{array}{l}\text { Pembuatan laporan } \\
\text { dan rekomendasi }\end{array}$ & $\begin{array}{l}1-15 \text { Des } \\
2014\end{array}$ & $\begin{array}{l}\text { Malaporkan hasil } \\
\text { evaluasi dan } \\
\text { memberikan } \\
\text { rekomendasi }\end{array}$ \\
& &
\end{tabular}

Pemilihan responden menggunakan purposive sampling, yaitu pemilihan responden yang ditentukan oleh peneliti dengan alasan bahwa identifikasi responden dilakukan dengan konsisten mengacu pada kompetensi personal yang peneliti anggap memiliki pengetahuan yang mendalam terhadap tata kelola TI dibandingkan dengan personal lainnya pada fungsional struktur di Kemendikbud.

\subsection{Model Kuesioner}

Pada penelitian ini pengumpulan data dilakukan dengan metode kuesioner yang telah dijadikan standar oleh Kementerian Komunikasi dan Informatika Republik Indonesia dalam menilai pemanfaatan TI berdasarkan standar Penilaian eGovernment Indonesia (PeGI). Terdiri dari 5 (lima) dimensi tata kelola yaitu Dimensi I (Kebijakan), Dimensi II (Kelembagaan), Dimensi III (Infrastruktur), Dimensi IV (Aplikasi) dan Dimensi V (Perencanaan)

a. Kuesioner I : Dimensi Kebijakan

Kuesioner ini dikembangkan untuk dapat mengidentifikasikan hal-hal yang berkaitan dengan produk hukum dan dokumen-dokumen resmi yang memberi arah dan mendorong pemanfaatan TIK dalam suatu organisasi yang terdiri dari antara lain: Visi dan Misi, Strategi Pemanfaatan TIK, Standar (laporan), Pedoman (misalnya keamanan informasi), Peraturan dan Kebijakan Anggaran. Kuesioner I berisi 8 kategori pertanyaan.

b. Kuesioner II : Dimensi Kelembagaan

Kuesioner ini dikembangkan untuk dapat mengidentifikasikan hal-hal yang berkaitan dengan keberadaan organisasi yang berwewenang dan bertanggung jawab terhadap pengembangan dan pemanfaatan TIK dengan indikator antara lain: Keberadaan organisasi struktural yang lengkap (menjalankan fungsi CIO, dukungan teknis dan lain lain), Tupoksi yang jelas, Kelengkapan unit dan aparatur (jumlah, kompetensi dan status), dan Legalitas (dasar hukum). Kuesioner II berisi 5 kategori pertanyaan.

c. Kuesioner III : Dimensi Infrastruktur

Kuesioner ini dikembangkan untuk dapat mengidentifikasikan hal-hal yang berkaitan dengan prasarana yang diperlukan untuk pengembangan dan pemanfaatan teknologi informasi dalam bentuk peralatan teknologi informasi dan fasilitas pendukungnya. Yang termasuk dalam infrastruktur antara lain: Server, jaringan data, Peranti keras tambahan (printer, scanner), Peranti lunak sistem operasi, peranti lunak basis data, Peranti penyimpanan data, Ruangan dan fasilitas pendukungnya $(A C$, listrik, kontrol akses).

Kuesioner III berisi 7 kategori pertanyaan. 
d. Kuesioner IV : Dimensi Aplikasi

Kuesioner ini dikembangkan untuk dapat mengidentifikasikan hal-hal yang berkaitan dengan ketersediaan dan tingkat pemanfaatan piranti lunak pendukung e-government yang sesuai dengan tugas dan fungsi instansi. Kuesioner IV berisi 10 kategori pertanyaan.

e. Kuesinoer V : Dimensi Perencanaan

Kuesioner ini dikembangkan untuk dapat mengidentifikasikan hal-hal yang berkaitan dengan perencanaan strategis TIK di instansi. Kuesioner IV berisi 5 kategori pertanyaan.

\subsection{Responden}

Pemilihan sampel responden menggunakan teknik purposive sampling, yaitu pemilihan sampel responden yang ditentukan oleh peneliti dengan alasan bahwa identifikasi sampel responden dilakukan dengan mengacu pada kompetensi personal yang berinteraksi langsung dengan tata kelola TI di Kemendikbud dibandingkan dengan personal lainnya (Tabel 2).

Tabel 2. Sumber data

\begin{tabular}{rll}
\hline No. & \multicolumn{2}{l}{ Dimensi PeGI } \\
\hline 1 & Dimensi I & : Kebijakan \\
2 & Dimensi II & : Kelembagaan \\
3 & Dimensi III & : Infrastruktur \\
4 & Dimensi IV & : Aplikasi \\
5 & Dimensi V & : Perencanaan \\
\hline
\end{tabular}

Adapun jumlah populasi personal yang pmengelola TIK di Kemendikbud (Pustekkom) ada sebanyak 227 orang. Dengan formasi 33 orang pada bagian pengembangan jejaring, 41 orang pada bidang pengembangan teknologi pembelajaran berbasis Multimedia dan Web, 83 orang pada bidang pengembangan teknologi pembelajaran berbasis Radio, Televisi dan Film dan 70 orang pada bagian Tata Usaha.

\section{Hasil dan Pembahasan}

Hasil rekapitulasi data secara keseluruhan terhadap 5 dimensi PeGI yang ada dapat dilihat pada gambar 2 .

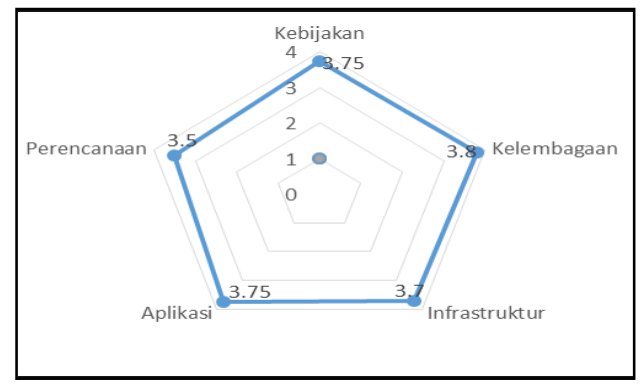

Gambar 2. Diagram hasil pengukuran pemanfaatan TIK di Kemendikbud
Dari hasil penilaian assessment implementasi $e$ gov dengan kerangka PeGI, Kemendikbud mendapat peringkat "Sangat Baik". Berikut diberikan pembahasan secara rinci.

a. Pembahasan Dimensi Kebijakan

Pada dimensi kebijakan dapat dilihat bahwa Kemendikbud telah memiliki Visi dan Misi tentang IT dan rencana induk teknologi informasi dan komunikasi (RITIK). Road map mengenai IT telah dituliskan dalam RITIK tersebut. Kemendikbud memiliki perencanaan dan kebijakan IT yang dituliskan yang dalam renstra (rencana strategis). Dalam hal mendukung kebijakan dan program TIK Kermendikbud telah memiliki anggaran khusus yang nilainya masih belum terlalu besar. Proses audit terkait hal IT dilakukan oleh internal dan eksternal Kemendikbud. Selain itu, Kemendikbud telah melakukan dokumentasi dengan baik pada setiap program, kebijakan, dan perencanaan TIK. Kekurangannya adalah Tidak adanya proses pola pengambilan kebijakan di bidang TIK.

b. Pembahasan Dimensi Kelembagaan

Pada dimensi kelembagaan kekurangannya adalah dokumentasi terkait SDM (Sumber Daya Manusia) beserta keahliannya belum dapat didokumentasikan dengan rapi, Kelebihannya adalah struktur organisasi terkait IT telah didefinisikan dengan jelas, terdapat unit khusus yaitu Pustekkom yang melayani IT untuk Kemendikbud seluruh Indonesia. Mengenai SOP (Standard Operating Procedure) telah didokumentasikan dengan baik disertai tugas, pokok, dan fungsi yang dilaksanakan dengan baik. Selain itu, Pengembangan SDM mengenai IT telah dilakukan sesuai dengan kebutuhan. Kekurangannya adalah jumlah tenaga SDM TIK yang tidak dapat diketahui dengan pasti sehingga tidak dapat diketahui dengan pasti, berapa perbandingan antara jumlah user dengan departemen TIK yang melayani.

c. Pembahasan Dimensi Infrastruktur

Pada bagian Infrastruktur Kemendikbud telah memiliki rancangan infrastruktur yang disebut jardiknas (jaringan pendidikan nasional). Kemendikbud telah memiliki data center yang terletak di ciputat, senayan dan surayabaya sedangkan untuk disaster recovery plan (DRC) terletak di surabaya. Teknologi pendukung untuk software dan hardware untuk operasional data center dan keamanan telah dimiliki dan dioperasionalkan dengan baik. Prosedur mengenai pemeliharaan TIK telah didokumentasikan dengan jelas. Kemendikbud memiliki satu buah mobile data center yang diletakkan didalam truk kontainer berfungsi untuk memudahkan apabila data center tersebut ingin dipindahkan. Kekurangannya adalah 
dokumentasi mengenai inventaris TIK di data center masih belum dicatat dengan baik.

d. Pembahasan Dimensi Aplikasi

Pada bagian aplikasi semua aplikasi yang dimiliki sudah berjalan dengan baik dan memiliki fungsi yang dapat mendukung organisasi dan memberikan layanan kepada publik. Hal tersebut dapat dilihat dengan Kemendikbud telah memiliki website resmi. Kemudian, Kemendikbud juga memiliki aplikasi yang untuk layanan publik seperti beasiswa, rumah belajar, tv pendidikan, dll. Untuk aplikasi yang melayani internal organisasi Kemendikbud telah memiliki seperti aplikasi keuanganm, kepegawaian dan aplikasi khusus unit unit tertentu. Kekurangannya adalah mengenai dokumentasi aplikasi yang belum lengkap dan sulit untuk ditemukan karena tidak diletakkan pada tempat khusus.

e. Pembahasan Dimensi Perencanaan

Pada bagian perencanaan Kemendikbud telah menjalankan organisasi / fungsi dengan baik, Master plan mengenai TIK telah didokumentasikan dengan baik. Kemudian, Kemendikbud telah menerapkan mekanisme proses perencanaan yang baku untuk setiap dimensi tata kelola. Selain itu, setiap aktivitas kemendikbud didokumentasikan ke dalam dokumen dokumen seperti renstra, KAK, RAB, DIPA, RKA-KL, dokumentasi perencanaan teknis aplikasi dan infrastruktur. Kekurangannya adalah belum adanya standarisasi mengenai layanan e-pendidikan, aplikasi dan infrastruktur dan pengembangan konten e-pendidikan.

Dari hasil penilaian tiap dimensi, kemudian dilakukan penilaian rata-rata terhadap indikator dari masing-masing dimensi Kemendikbud. Hasil rata-rata penilaian dimensi dapat dilihat pada Tabel 3.

Tabel 3. Peringkat PeGI Kemendikbud

\begin{tabular}{cll}
\hline No & Dimensi & Skor \\
\hline 1 & Dimensi I : Kebijakan & 3.75 \\
2 & Dimensi II : Kelembagaan & 3.80 \\
3 & Dimensi III : Infrastruktur & 3.7 \\
4 & Dimensi IV : Aplikasi & 3.75 \\
5 & Dimensi V : Perencanaan & 3.5 \\
\hline Skor & Rata-Rata & 3.7 \\
\hline
\end{tabular}

Berdasarkan hasil penilaian pada peringkat PeGI, diberikan rekomendasi sebagai bahan untuk untuk meningkatkan PEGI :

a. Tata Kelola TIK harus menjadi kebijakan formal Kemdikbud, sehingga ada mekanisme "reward and punishment" di seluruh jajaran Kemendibud.

b. Hendaknya Rencana Induk TIK (RITIK) harus dimutakhirkan agar selaras dengan rumusan Tata Kelola TIK. c. Melengkapi dokumen untuk jumlah dan spesifikasi dari tenaga SDM TIK dengan detil tiap untuk unit kerja, sehingga dapat mengevaluasi kebutuhan SDM TIK kedepannya.

d. Pencatan terkait inventaris aplikasi dikumpulkan menjadi sebuah dokumen sehingga mudah untuk dicari, dan diolah.

e. Pencatan dokumentasi tiap aplikasi perlu dirapihkan sehingga ketika dicari dapat ditemukan dengan mudah

f. Penamaan domain masih terdapat perbedaan antara kemdiknas dan kemdikbud. Sehingga perlu disamakan semua aplikasi menggunakan nama domain yang sama yaitu kemdikbud.

g. Penggunaan data dalam Kementerian dapat terintegrasi sehingga tidak banyak terjadi duplikasi data.

h. Standarisasi layanan e-Pendidikan.

i. Melengkapi desain manajemen dan organisasi SI/TI dengan hal-hal sebagai berikut:

- Mekanisme koordinasi dan konsolidasi ePendidikan antara pusat, provinsi, dan kabupaten/kota.

- Strategi peningkatan kualitas dan kuantitas SDM pengelola layanan e-Pendidikan.

j. Melengkapi rencana pengembangan konten ependidikan dengan hal-hal sebagai berikut:

- Standar pengembangan konten e-pendidikan

- Strategi peningkatan kualitas dan kuantitas SDM pengelola dan pengembang konten ePendidikan.

k. Melengkapi rencana pengembangan sistem dan teknologi informasi dengan hal-hal sebagai berikut:

- Peta tematik kesiapan infrastruktur TIK satuan pendidikan dan satuan kerja berdasarkan area jangkauan jaringan listrik dan internet.

- Standar minimum perangkat dan jaringan untuk e-Pembelajaran di satuan pendidikan dan e-administrasi di satuan kerja.

\section{Kesimpulan}

Dari hasil analisis strategi pengembangan egovernment menggunakan kerangka kerja PeGI studi kasus pada Kemendikbud didapatkan kesimpulan, bahwa hasil assessment implementasi egovernment pada Kementerian Pendidikan dan Kebudayaan adalah 3,7. Secara umum pemanfaatan TIK di Kemendikbud untuk tahun 2014 sudah memiliki kriteria "Sangat Baik", dimana sejumlah indikator, memiliki kualitas yang sangat baik, hanya ada sedikit kelemahan dimensi-dimensi aplikasi dan infrastruktur.

Hasil penelitian juga menunjukkan bahwa pada implementasi e-government Kementerian Pendidikan dan Kebudayaan, pada aspek perencanaan bernilai 3.5. Walaupun menurut standar penilaian nilai ini 
sudah memiliki nilai yang baik, namun dibandingkan dengan nilai yang dimiliki aspek lain, aspek perencanaan dapat terus diperbaiki dan dikembangkan, karena perencanaan menjadi dasar proses tata kelola.

Untuk meningkatkan peringkat PeGI, diberikan beberapa rekomendasi perbaikan diantaranya: hendaknya Tata Kelola TIK harus menjadi kebijakan formal Kemdikbud dan disusun kebijakan terkait Tata Kelola TIK yang selaras dengan Rencana Induk TIK (RITIK) rumusan Tata Kelola TIK, melengkapi dokumen yang terkait dengan SDM TIK, melengkapi dokumen aplikasi, standarisasi penamaan domain, standarisasi layanan e-pendidikan, kelengkapan desain manajemen dan organisasi SI/TI, melengkapi rencana pengembangan konten e-pendidikan, melengkapi rencana pengembangan sistem dan teknologi informasi.

Selanjutnya, dari hasil assessment, diberikan beberapa saran. Untuk mempertahankan tingkat implementasi e-Government di pada Kementerian Pendidikan dan Kebudayaan, diperlukan strategi yang tepat dan sesuai dengan lingkungan organisasi. Pada Penelitian ini hanya menggunakan indikator metode yaitu metode PeGI, untuk penelitian lanjut diharapkan dapat melakukan komparasi atau menambahkan metode pengukuran PeGI dengan metode pengukuran metode lainnya, agar dapat menguatkan hasil yang diperoleh. Hasil pengukuran yang diperoleh diusulkan sebagai bahan pertimbangan bagi pada Kementerian Pendidikan dan Kebudayaan untuk mendorong pemanfaatan TIK dan menjadi kerangka acuan dalam mengevaluasi tata kelola teknologi informasi, mana saja yang telah dilakukan dan yang perlu diperbaiki dalam implementasi aplikasi e-Government.

\section{Daftar Pustaka}

Kemenpan, 2011. Peraturan Menteri Pemberdayaan Aparatur Negara dan Reformasi Birokrasi No.11 tahun 2011 tentang Indikator Keberhasilan Reformasi Birokrasi, Jakarta.

Kementerian Pendidikan dan Kebudayaan, 2010. Buku renstra e-Pendidikan periode 2010-2014.

Laporan Akuntabilitas Kinerja (LAKIP), 2013. http://www.kemdiknas.go.id/kemdikbud/tentan g-kemdikbud-lakip, diakses terakhir 14 Desember 2014.

Kementerian Pendidikan dan Kebudayaan, 2012. Laporan Keuangan Kemdikbud 2012-Audited http://www.kemdiknas.go.id/kemdikbud/tentan g-kemdikbud-keuangan/ diakses terakhir 14 Desember 2014.
Kementerian Pendidikan dan Kebudayaan, 2012. Laporan Keuangan Kemdikbud 2013Unaudited,

http://www.kemdiknas.go.id/kemdikbud/tentan g-kemdikbud-keuangan/ diakses terakhir 14 Desember 2014.

Kementerian Pendidikan dan Kebudayaan, 2010. Model sistem layanan berbasis TIK [Draft], Tim Reformasi Birokrasi Internal Pustekkom Kemdikbud.

Kementerian Pendidikan dan Kebudayaan, 2014. profil Pustekkom, http://setjen.kemdikbud.go.id/pustekkom/halprofil.html, diakses terakhir 14 Desember 2014.

Kementerian Pendidikan dan Kebudayaan, 2010. Renstra Kementerian Pendidikan dan Kebudayaan periode 2010-2014, http://www.kemdiknas.go.id/kemdikbud/tentan g-kemdikbud-renstra, diakses terakhir 14 Desember 2014.

Kemkominfo, 2012. Pemeringkatan E- Government Indonesia [slide Materi Dimensi Pemeringkatan dan Formulir Assesment]. Jakarta.

Kemkominfo, 2011. Surat Edaran Menteri Komunikasi dan Informatika Nomor:07/SE/M.KOMINFO/10/2011 tentang Pemeringkatan e-Government Indonesia (PeGI). Jakarta.

Kementerian Pendidikan dan Kebudayaan, 2013. Permen RI No. 99 Tahin 2013 tentang Tata Kelola TIK di lingkugan Kementerian Pendidikan dan Kebudayaan Republik Indonesia.

Pustekkom, 2013. Tata Kelola Teknologi Informasi dan Komunikasi Kementerian Pendidikan dan Kebudayaan Republik Indonesia [slide presentasi Tata Kelola TIK di Kementerian Pendidikan dan Kebudayaan RI].

Republik Indonesia, 2003. Instruksi Presiden No.6 Tahun 2001 tentang Telematika (Telekomunikasi, Media dan Informatika), Jakarta.

Republik Indonesia, 2003. Instruksi Presiden No.3 Tahun 2003 tentang Kebijakan dan Strategi Nasional Pengembangan e-Government, Jakarta.

United Nations, 2014. E-Government Survey 2014 "e-government for the future", United Nations, New York published. 